\title{
Surfaces and Air Bacteriology of Selected Wards at a Referral Hospital, Northwest Ethiopia: A Cross-Sectional Study
}

\author{
Hailu Getachew, ${ }^{1}$ Awoke Derbie $\mathbb{D D}^{2}$ and Daniel Mekonnen (D) $^{2}$ \\ ${ }^{1}$ Amhara Public Health Institute (APHI), Bahir Dar, Ethiopia \\ ${ }^{2}$ Department of Medical Microbiology, College of Medicine and Health Sciences, Bahir Dar University, Bahir Dar, Ethiopia
}

Correspondence should be addressed to Awoke Derbie; awe.love2000@gmail.com

Received 22 February 2018; Accepted 24 April 2018; Published 13 May 2018

Academic Editor: Barbara H. Iglewski

Copyright (C) 2018 Hailu Getachew et al. This is an open access article distributed under the Creative Commons Attribution License, which permits unrestricted use, distribution, and reproduction in any medium, provided the original work is properly cited.

\begin{abstract}
Background. The hospital environment is a source of medically important pathogens that are mostly multidrug resistant (MDR) and posing a major therapeutic challenge. The aim of this study was to assess the surface and air bacteriology of selected wards at Felege Hiwot Referral Hospital (FHRH), Northwest Ethiopia. Methods. A cross-sectional study was carried out from 15th February to 30th April 2017. A total of 356 surface and air samples were collected from selected wards using 5\% sheep blood agar (Oxoid, UK) and processed at FHRH microbiology laboratory following the standard bacteriological procedures. Pure isolates were tested against the recommended antibiotics using Kirby-Bauer disc diffusion methods, and the susceptibility profile was determined based on Clinical Laboratory Standards Institute (CLSI). Data were entered and analyzed using SPSS version 23 for Windows. Results. Of the total 356 samples processed, 274 were from surfaces and 82 were from air. Among these, 141 (39.6\%) showed bacterial growth, yielding a total of 190 isolates. Gram-positive isolates were predominant at $81.6 \%(n=155)$, while the gram negatives were at $18.4 \%(n=35)$. The main isolates were coagulase negative staphylococci $(\mathrm{CoNs})$, $44 \%$, followed by $S$. aureus, $37.4 \%$, and Klebsiella species at $11.6 \%$. The bacterial load on surfaces and air was found beyond the standard limits. Besides, the antimicrobial susceptibility profile of the isolates showed that about $75 \%$ of the identified isolates were found resistant for two and more antimicrobial agents tested. Conclusions. This study showed high degree of bacterial load that is beyond the standard limits on both surfaces and air samples of the hospital. Furthermore, some $75 \%$ of the isolates were found multidrug resistant. Therefore, it is important to evaluate and strengthen the infection prevention practice of the hospital. Moreover, stakeholders should also reinforce actions to decrease the pressure of antimicrobial resistance in the studied area.
\end{abstract}

\section{Background}

Nosocomial infections (NIs) are infections acquired in a hospital or healthcare service unit that appear 48 hours or more after hospital admission or within 3 days after discharge [1]. The hand contact surfaces, floors, and air of the hospital environments are the main source of different pathogens that can cause NIs $[2,3]$. About $5 \%$ to $10 \%$ of admitted patients to modern hospitals in the western countries acquire one or more NIs $[4,5]$. In contrast, the magnitude of NIs is much higher in the developing countries due to different reasons [6] like poor ventilation system, high dusting, overcrowded setting, spread through sneezing and coughing, high movement of personnel, and suboptimal management of the hospital environment [7]. The hospital environment is the highest dissemination reservoir of pathogenic microbes which cause big challenges in the hospital environment, particularly in terms of NIs because it contains diverse population of microorganisms [7].

Microorganisms such as bacteria, fungi, and viruses can cause NIs. Reports showed that bacteria are much more important on this regard $[8,9]$. The most common organisms usually associated with NIs are $S$. aureus, CoNs, Pseudomonas aeruginosa, E. coli, Klebsiella species, and proteus species that would source from patients, health personnel, attendants, contaminated instrument, and the environment [10-12]. Most strains of bacteria in the health service environments are multidrug resistant (MDR) [13]. 
The wide spread use of drugs, especially over or inappropriate use of antibiotics, has contributed to an increased incidence of antimicrobial resistant organisms, especially in developing countries [14-16].

Studies on bacteriological quality of wards of healthcare facilities in Ethiopia are scarce, and the few available ones reported unacceptably high bacterial load $[13,17]$. Nationally, infection prevention guideline has been developed for healthcare facilities in Ethiopia. However, adherence of the healthcare providers to the protocol is quite limited [18] that could play a role for poor microbiological quality in different health facilities [19].

Based on our observation, in the present study setting, there were a number of health science students and high patient and patients' family trafficking in each ward of FHRH. Furthermore, there was poor restriction for entry of unauthorized individuals to access the different units of the hospital. Many wards were highly condensed and were not well ventilated. With this background and availability of quite limited data on the subject in the study area, this study was conducted to determine the degree of bacterial contamination and their antibiotic susceptibility profile from selected wards at Felege Hiwot Referral Hospital (FHRH) as part of infection prevention service auditing.

\section{Materials and Methods}

2.1. Study Setting, Design, and Period. We have conducted a hospital-based cross-sectional bacteriological study from 15 February to 30 April 2017 at FHRH, Bahir Dar, Northwest Ethiopia. Bahir Dar city is located about $565 \mathrm{~km}$ away from Addis Ababa, the capital of Ethiopia. FHRH was established in 1952 and was serving more than 10 million people of Bahir Dar and the surrounding zones and regions. The hospital had 13 wards, 430 beds, and about 531 health professionals during the period of data collection. The daily outpatient clients were more than 600 . The hospital was also hosting medical and other health science students of Bahir Dar University and private colleges for practical attachments.

The authors had observational assessment in each ward during the sample collection period to assess the environmental cleanliness, number of occupants in each room, the use and type of disinfectants, the situation of ventilation, preparation of disinfectants, and frequency of cleaning. Based on our observation, all ward floors were cleaned with solution containing bleach three times a day. Dry sweeping was practiced before mopping which might suspend pathogens in the air. There was no mechanical ventilation system in any of the wards. Only the natural air circulates in the rooms which may increase the possibility of entrance of organisms from the outside environments. In all wards, we have observed no regular cleaning practice of hand contact surfaces such as walls, chairs, beds, intravenous (IV) stands, and stretchers. On the contrary, regular cleaning practice in all healthcare workers personal protective equipments was practiced. However, there was poor practice of removal and discarding of personal protective equipment prior to leaving the patient room.
2.2. Bacteriological Sampling and Culture. A total of 356 surface and air bacteriological samples were collected for analysis. Considering the number of patient flow and the safety of critically ill patients, the following hospital environments were included for sampling: Operation theater (OT), surgical wards, intensive care unit (ICU), neonatal intensive care unit (NICU), dialysis and obstetrics, maternity, and orthopedics. The rest areas of the hospital were excluded.

The air samples were collected two times per day: in the morning between $10 \mathrm{am}$ and $11 \mathrm{am}$ and in the afternoon between $1 \mathrm{pm}$ and $2 \mathrm{pm}$, taking the consideration of high human trafficking in these time intervals. Samples were collected as per the standard protocol using the settle plate or passive air sampling method following the 1/1/1 schedule (on $90 \mathrm{~mm}$ diameter sterile petri dishes containing 5\% sheep's blood agar left on the air for 1 hour, 1 meter above the floor, and 1 meter away from the wall) [20]. During air sampling procedure, sterile gloves, surgical masks, and protective gowns were used to prevent contamination of the agar plates. Plates were checked visually for any bacterial growth before it was used.

Similarly, sterile cotton swabs moistened with sterile normal saline were used to collect surface samples on $1 \mathrm{~cm}$ by $1 \mathrm{~cm} \cdot$ area $/ \mathrm{cm}^{2} /$ surfaces such as the floor, walls, equipment, instruments, operation tables, sink, light switch, chairs, beds, patient cloths, door/locker handlers, trolley, stretchers, sinks/faucets, intravenous stands, and oxygen cylinder [21]. All type samples were labeled properly and transported to FHRH Microbiology laboratory within 30 minutes for microbiological analysis.

Both air and surfaces samples were inoculated on blood agar plates and incubated at $37^{\circ} \mathrm{C}$ for $18-24$ hours. Identification of the isolates was done based on the standard microbiological procedures. Colony characteristics, gram reaction, and conventional different biochemical tests were used to identify the isolates [22]. Microbial concentration of air was expressed as interims of colony-forming units (CFUs) using colony counter, and the results were expressed in $\mathrm{cfu} / \mathrm{dm}^{2} / \mathrm{hr}$ as described previously [23]. Similarly, swab culture result was expressed in colony-forming units using colony counter, and results were expressed in $\mathrm{cfu} / \mathrm{cm}^{2}$ [21].

\subsection{Antimicrobial Susceptibility Testing. Antimicrobial} susceptibility profile of the isolates was performed based on the Kirby-Bauer agar disc diffusion method. The suspension of the identified test organism was prepared from similar colonies. The densities of suspension were determined by comparing with McFarland 0.5 Barium sulfate solutions [24]. A sterile swab dipped into the suspension of the isolate in broth and then speeded over the entire surface of the Muller-Hinton agar plate (Oxoid, LTD). Then, the antibiotic disks were placed on the surface of inoculated agar and incubated at $37^{\circ} \mathrm{C}$ for $18-24$ hours. The diameters of the growth inhibition of discs were measured and interpreted as per the Clinical Laboratory Standards Institute (CLSI) guideline [25]. The drugs tested for both gram negative and gram positives were ciprofloxacin $(5 \mu \mathrm{g})$, gentamicin $(10 \mu \mathrm{g})$, 
tetracycline $(30 \mu \mathrm{g})$, cotrimoxazole $(25 \mu \mathrm{g})$, chloramphenicol $(30 \mu \mathrm{g})$, ceftriaxone $(30 \mu \mathrm{g})$, norfloxacillin $(10 \mu \mathrm{g})$, and Augmentin $(30 \mu \mathrm{g})$. Ampicillin $(10 \mu \mathrm{g})$ was tested only for gram negatives. In contrast, penicillin (10 IU), erythromycin $(15 \mu \mathrm{g})$, cefoxtin $(30 \mu \mathrm{g})$, doxycyclin $(30 \mu \mathrm{g})$, clindamycin $(2 \mu \mathrm{g})$, and clarithromycin $(15 \mu \mathrm{g})$ tested for gram positives [25].

2.4. Data Analysis. All data were entered, cleaned, and analyzed using Statistical Software Package for Social Sciences (SPSS) version 23 (SPSS Inc., Chicago, IL, USA) for Windows. Generated data were compiled and presented using descriptive statistics.

2.5. Quality Control. The reliability of the study findings was guaranteed through the implementation of standard quality control (QC) measures throughout the whole processes of the laboratory works. All culture plates were prepared according to the manufacturers' instructions. Control bacteria strains, like Escherichia coli (ATCC 25922), S. aureus (ATCC 25923), and Pseudomonas aeruginosa (ATCC 27853), were used to ensure the quality of culture plates and antimicrobial susceptibility testing discs [25].

\subsection{Operational Definitions}

(i) Indoor air: the air inside the rooms of the selected wards.

(ii) Settle plate or passive air sampling: Petri dishes containing blood agar plates are left open to air for a given period of time. Microbes carried by inert particles fall onto the surface of the nutrient, with an average deposition rate of $0.46 \mathrm{~cm} / \mathrm{s}$ being reported [20].

(iii) $M D R$ bacteria: those bacterial isolates that are resistant to two or more antimicrobial agents tested.

\section{Results}

3.1. Bacterial Profile of Surfaces and Air. A total of 356 samples (274 surfaces and 82 air samples) were analyzed, of which some 141 (39.6\%) showed bacterial growth yielding a total of 190 isolates. Mixed growth was reported on 42 (29.8\%) samples. Gram-positive isolates were predominate at $155(81.6 \%)$ followed by gram negatives, $35(18.4 \%)$. Majority of the isolated bacteria at $102(53.7 \%)$ were recovered from air, and the rest at 88 (46.3\%) were from surfaces (Figure 1). The distribution of the isolates from surfaces includes door/locker handlers and floors (each account at $n=12)$, linen and patient cloth $(n=11)$, chairs $(n=10)$, light switch $(n=9)$, and sink $(n=8)$.

Concerning the identified bacteria, the predominant isolates were coagulase negative staphylococci $(\mathrm{CoNs})$ at $44 \%$, followed by S. aureus at $37.4 \%$, and Klebsiella species at $11.6 \%$. $S$. aureus were isolated from the surgical ward and maternity ward at $19(26.8 \%)$ each followed by orthopedics and the

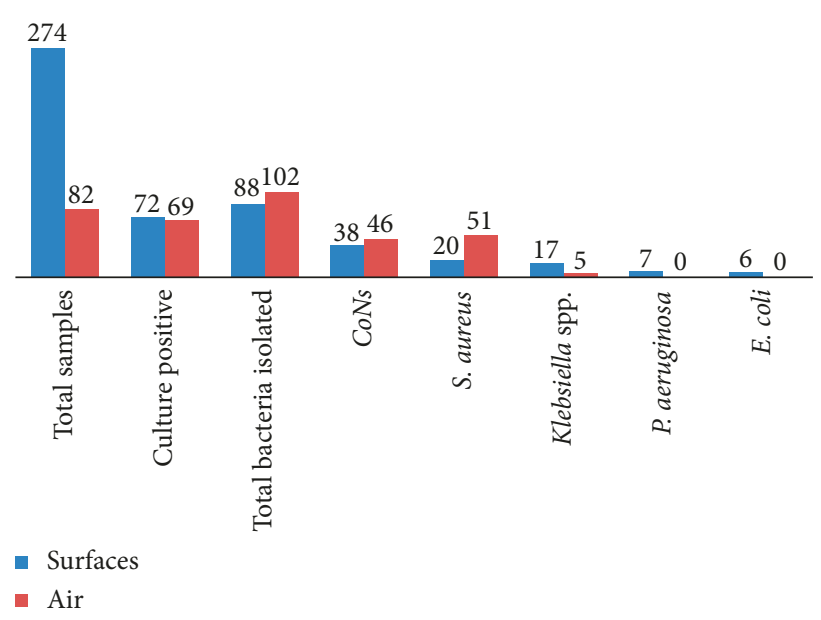

FIgURE 1: Types and frequency of bacterial isolates identified from the surface and of FHRH, 2017.

TABLE 1: Mean bacterial counts from air sample at FHRH, 2017 $[20,26]$.

\begin{tabular}{|c|c|c|c|c|}
\hline \multirow[b]{2}{*}{ Site } & \multirow{2}{*}{$\begin{array}{c}\text { Mean } \\
\text { bacterial load } \\
\mathrm{Cfu} / \mathrm{dm}^{2} / \mathrm{hr}\end{array}$} & \multicolumn{3}{|c|}{ Standard $\left(\mathrm{cfu} / \mathrm{dm}^{2} / \mathrm{hr}\right)^{*}$} \\
\hline & & Optimal & Acceptable & Unacceptable \\
\hline $\begin{array}{l}\text { Surgical } \\
\text { ward }\end{array}$ & $721 \mathrm{cfu} / \mathrm{dm}^{2}$ & $0-250$ & $251-450$ & $>450$ \\
\hline OR (active) & $294.4 \mathrm{cfu} / \mathrm{dm}^{2}$ & $0-60$ & $61-90$ & $>90$ \\
\hline Maternity & $619.3 \mathrm{cfu} / \mathrm{dm}^{2}$ & NS & $251-451$ & $>451$ \\
\hline NICU & $292.8 \mathrm{cfu} / \mathrm{dm}^{2}$ & NS & $51-90$ & $>90$ \\
\hline ICU & $246.9 \mathrm{cfu} / \mathrm{dm}^{2}$ & $0-250$ & $251-450$ & $>450$ \\
\hline Orthoped & $580.2 \mathrm{cfu} / \mathrm{dm}^{2}$ & NS & NS & NS \\
\hline Dialysis & $135.8 \mathrm{cfu} / \mathrm{dm}^{2}$ & NS & NS & NS \\
\hline
\end{tabular}

${ }^{*}$ Debatable whether the listed standards are commonly accepted; NS, no standard set.

operation theatre at $12(17 \%)$ each, and $18(81.8 \%)$ of the Klebsiella spp. was also isolated in surgical wards.

When we look at the distribution of isolates from different wards, the highest bacterial growth was recovered from the surgical ward at $62(32.6 \%)$ followed by maternity, orthopedics, and operation theatres with 49 (25.9\%), 31 (16.3\%), and 29 (15.3\%), respectively. The least bacterial growth was documented in NICU, ICU, and dialysis rooms at 12 (6.3\%), 5 $(2.6 \%)$, and $2(1 \%)$, respectively.

3.2. Bacterial Load from Air. The authors determined the degree of bacterial load from air of different wards based on the recommended approach. In terms of the distribution of wards, the highest numbers of bacteria isolates were identified from the surgical ward at $30.2 \%$ followed by maternity wards at $26.5 \%$, orthopedics, and NICU with $9.8 \%$ each.

The profile of bacterial load of an open-air in terms of colony-forming units $/ \mathrm{dm}^{2}$ is presented in Table 1 . The highest load which was found beyond the standard limit at $721 \mathrm{cfu} / \mathrm{dm}^{2}$ and $619.3 \mathrm{cfu} / \mathrm{dm}^{2}$ was reported in the surgical and maternity wards, respectively. However, compared with the other wards, the bacterial load in the dialysis room was the 
TABLE 2: Distribution of antimicrobial resistance profile of bacterial pathogens isolated from surfaces and air at FHRH, 2017.

\begin{tabular}{|c|c|c|c|c|c|}
\hline \multirow{2}{*}{ Antibiotics } & \multicolumn{5}{|c|}{ Bacteria isolates and their antibiotic resistance pattern } \\
\hline & S. aureus $(n=71)$ & CoNs $(n=84)$ & Klebsiella spp. $(n=22)$ & P. aeruginosa $(n=7)$ & E. $\operatorname{coli}(n=6)$ \\
\hline Cotrimoxazole & $35(49.5 \%)$ & $48(57.7 \%)$ & $8(36.4 \%)$ & $7(100 \%)$ & $6(100 \%)$ \\
\hline Chloramphenicol & $20(28 \%)$ & $26(31 \%)$ & $7(32 \%)$ & $4(57.2 \%)$ & $4(66.7 \%)$ \\
\hline Gentamicin & $19(26.7 \%)$ & $26(30.5 \%)$ & $9(41 \%)$ & $2(28.6 \%)$ & $4(66.7 \%)$ \\
\hline Tetracycline & $29(41 \%)$ & $45(53.4 \%)$ & $7(32 \%)$ & $5(71.6 \%)$ & $4(66.7 \%)$ \\
\hline Cefoxtin & $18(25 \%)$ & $24(29 \%)$ & NA & NA & NA \\
\hline Clindamycin & $12(16.3 \%)$ & $14(17.2 \%)$ & NA & NA & NA \\
\hline Doxycyclin & $17(24.5 \%)$ & $24(29 \%)$ & NA & NA & NA \\
\hline Erythromycin & $54(75.5 \%)$ & $59(70.2 \%)$ & NA & NA & NA \\
\hline Clarithromycin & $50(70 \%)$ & $66(78.5 \%)$ & NA & NA & NA \\
\hline Ciprofloxacin & $16(22.5 \%)$ & $20(24 \%)$ & $5(23 \%)$ & $6(85.7 \%)$ & $4(66.7 \%)$ \\
\hline Norfloxacillin & $17(24 \%)$ & $19(22.6 \%)$ & $4(18.2 \%)$ & $0(0 \%)$ & $2(33.3 \%)$ \\
\hline Augmentin & $16(22.5 \%)$ & $16(19 \%)$ & $5(23 \%)$ & IR & $3(50 \%)$ \\
\hline Penicillin & $60(84.5 \%)$ & $74(88 \%)$ & NA & NA & NA \\
\hline Ceftriaxone & $23(32.4 \%)$ & $54(64 \%)$ & $9(41 \%)$ & IR & $1(12.7 \%)$ \\
\hline Ampicillin & NA & NA & $12(54.6 \%)$ & IR & $6(100 \%)$ \\
\hline
\end{tabular}

NA, not applicable; Augmentin, amoxicillin/clavulanic acid; IR, intrinsic resistance.

TABLE 3: Multidrug-resistant (MDR) profile of the isolates from surface and air of FHRH, 2017.

\begin{tabular}{|c|c|c|c|c|c|c|}
\hline \multirow{2}{*}{ Types of spp. } & \multicolumn{6}{|c|}{ Antibiogram profile } \\
\hline & R0 & $\mathrm{R} 1$ & R2 & R3 & $\mathrm{R} 4$ & $\geq \mathrm{R} 5$ \\
\hline Gram positive & $9(5.8 \%)$ & $18(11.6 \%)$ & $15(9.7 \%)$ & $27(17.4 \%)$ & $14(9 \%)$ & $72(46.6 \%)$ \\
\hline S. aureus & $8(11.3 \%)$ & $8(11.3)$ & $14(19.7 \%)$ & $11(15.5 \%)$ & $6(8 \%)$ & $24(33.8 \%)$ \\
\hline CoNs & $1(1.2 \%)$ & $10(11.9 \%)$ & $1(1.2 \%)$ & $16(19 \%)$ & $8(9.5 \%)$ & $48(57.1 \%)$ \\
\hline Gram negative & $4(11.4 \%)$ & $9(25.7 \%)$ & $3(8.6 \%)$ & $2(5.7 \%)$ & $1(2.9 \%)$ & $16(45.7 \%)$ \\
\hline Klebsiella spp. & $4(18.2 \%)$ & $9(40.9 \%)$ & $1(4.5 \%)$ & $1(4.5 \%)$ & 0 & $7(31.8 \%)$ \\
\hline E. coli & 0 & 0 & $2(33.3 \%)$ & 0 & 0 & $4(66.7 \%)$ \\
\hline P. aeruginosa & 0 & 0 & 0 & $1(14.3 \%)$ & $1(14.3 \%)$ & $5(71.4 \%)$ \\
\hline Total & $13(9.8 \%)$ & $28(14.7 \%)$ & $18(9.5 \%)$ & $29(15.3 \%)$ & $30(15.8 \%)$ & $88(46.3 \%)$ \\
\hline
\end{tabular}

$\mathrm{R} 0=$ sensitive to all drugs, $\mathrm{R} 1=$ resistance to one drug, $\mathrm{R} 2=$ resistance to two drugs, $\mathrm{R} 3=$ resistance to three drugs, $\mathrm{R} 4=$ resistance to four drugs, and $\mathrm{R} 5=$ resistance to five drugs.

least at $135.8 \mathrm{cfu} / \mathrm{dm}^{2}$. In the investigated rooms, the highest mean bacterial colony-forming units (CFUs) were recorded in the morning (10:00-11:00 am) at $482.8 \mathrm{cfu} / \mathrm{dm}^{2}(59.5 \%)$ compared with the afternoon $(1: 00-2: 00 \mathrm{pm})$ at $329 \mathrm{cfu} / \mathrm{dm}^{2}$ (40.5\%).

3.3. Bacterial Load from Surface. The mean aerobic colony count (ACC) from surfaces in the hospital was higher than the acceptable limits, at $<5 \mathrm{cfu} / \mathrm{cm}^{2}$ [21]. The mean total aerobic colony counts from all surfaces in the investigated wards were at $31.5 \mathrm{cfu} / \mathrm{cm}^{2}$. The highest mean bacterial colony number was reported in surgical wards at $48.8 \mathrm{cfu} / \mathrm{cm}^{2}$ followed by maternity, orthopedics, NICU, and ICU at $45.9 \mathrm{cfu} / \mathrm{cm}^{2}$, $34.9 \mathrm{cfu} / \mathrm{cm}^{2}, 27.5 \mathrm{cfu} / \mathrm{cm}^{2}$, and $16.5 \mathrm{cfu} / \mathrm{cm}^{2}$, respectively, and the least was in the OT at $14.8 \mathrm{cfu} / \mathrm{cm}^{2}$. No bacteria were isolated from the dialysis room.

3.4. Antimicrobial Resistance Profile of the Isolates. The gram-positive isolates, CoNs, showed high level of resistance against penicillin, clarithromycin, and erythromycin at $88 \%, 78.5 \%$, and $70.2 \%$, respectively. In contrast, these isolates showed low level of resistance to clindamycin, amoxicillin/clavulanic acid, and norfloxacillin at $17.2 \%$, $19 \%$, and $22.6 \%$, respectively.
Similarly, S. aureus isolates also showed high level of resistance against penicillin, erythromycin, and clarithromycin at $84.5 \%, 75.5 \%$, and $70 \%$, respectively. Low level resistance at $16.3 \%, 22.5 \%, 22.5 \%$, and $23.3 \%$ was documented against clindamycin, ciprofloxacin, amoxicillin/clavulanic, and Norfloxacillin, respectively.

On the other hand from gram-negative isolates, E. coli showed $100 \%$ resistance for ampicillin and cotrimoxazole. In contrast, lower level of resistance at $12.7 \%$ and $33.3 \%$ against ceftriaxone and norfloxacillin, respectively, was documented for E. coli (Table 2).

The overall drug resistance profile of the isolated bacteria showed that some 72 (46.6\%) of gram-positive bacteria were resistant for five and more antimicrobial agents tested. Similarly, about 16 (45.7\%) of gram-negative isolates were found resistant to five and more antimicrobial agents tested. About 5 of 190 isolates were found resistant to all of the antibiotics tested (Table 3 ).

\section{Discussions}

Different studies had reported that air and hand contact surfaces of the healthcare service units are contaminated by different pathogens which might serve as source of 
infections. This study was carried out to gain an insight into the distribution, frequency, bacterial load, and antimicrobial susceptibility profile of pathogens at the setting of FHRH, which is one of the busiest hospitals in Northwestern Ethiopia.

The aerobic culture results revealed that about 141 $(39.6 \%)$ surfaces and air samples were found contaminated by various bacterial pathogens. This finding is relatively lower than other similar studies done in Ethiopia and abroad in Nigeria that reported bacterial growth at $52.9 \%$ and $65.7 \%$, respectively $[11,27]$. In the present study, about $81.6 \%$ of the isolates were gram positive which is in line with previous studies done in Ayder Hospital, Ethiopia, that reported $87.3 \%$ [16]. In contrast, lower distribution of gram positives at $43.1 \%$ was reported in Hawassa, Ethiopia [14]. The higher frequency of the gram positives might be due to the dry conditions of the hospital environment and transmission from skin, nasal, and boils of healthcare workers and patients as described previously [7, 28].

When we see the specific type of the isolates, CoNs at 84 (44.2\%), S. aureus at $71(37.4 \%)$ and Klebsiella species at 22 $(11.6 \%)$ were the predominant. All of these are known nosocomial pathogens especially in surgical ward, OT \& admitted immune-suppressed patients in hospital setting [12]. This result was found concurring with studies carried out in another parts of Ethiopia, Ayder and Hawassa University Hospitals $[16,29]$ but disagree with the one done in Mexico [30]. It was in surgical ward where the highest number of isolates recovered at $34.9 \%$ from air and surface samples compare with other selected wards which imply that the risk of contracting nosocomial infections in this ward would be higher.

From the total hospital air samples processed during the study period, about 69 (84.1\%) showed bacterial growth. This entailed that numerous pathogenic bacteria could remain suspended in the air. Our finding is similar with a study done in Hawassa where the recovery rate from air was at 96.9\% and Gondar University Hospital at $81.1 \%[11,14]$. The mean bacterial load in the air of the surgical ward, $721 \mathrm{cfu} / \mathrm{dm}^{2}$, and maternity ward, $619.3 \mathrm{cfu} / \mathrm{dm}^{2}$, was beyond the standards $\left(250-450 \mathrm{cfu} / \mathrm{dm}^{2}\right)$ set by Fisher et al. [26] and Pasquarella et al. [20]. However, similar findings were reported in the surgical ward at Jima University hospital at $463 \mathrm{cfu} / \mathrm{dm}^{2}$ [13]. In contrast, the reported bacterial load in ICU was at $246.9 \mathrm{cfu} / \mathrm{dm}^{2}$ which is in line with the standard, although different figures are presented by other studies done in Nigeria \& Hawassa at $514 \mathrm{cfu} / \mathrm{dm}^{2}$ and $454.4 \mathrm{cfu} / \mathrm{dm}^{2}$, respectively $[7,15]$. In the present study, the bacterial load of the OR (during active time) was at $249.4 \mathrm{cfu} / \mathrm{dm}^{2}$ which was three times higher than the standard limit that is indeed unacceptable. The possible explanation for the reported high load of mean aerobic bacterial counts could be due to poor ventilation and cleaning practices and high and unrestricted human trafficking, particularly medical/health science students who were attached in the hospital as part of their practical learning process. Comparable finding was reported on studies done in the other parts of Ethiopia $[15,16]$.

In the present study, the reported mean aerobic colony count from surface samples collected in the surgical ward, ICU, orthopedics, OT, maternity ward, dialysis, and NICU units was at $48.8 \mathrm{cfu} / \mathrm{cm}^{2}, 16.5 \mathrm{cfu} / \mathrm{cm}^{2}, 34.9 \mathrm{cfu} / \mathrm{cm}^{2}$, $14.6 \mathrm{cfu} / \mathrm{cm}^{2}, \quad 45.9 \mathrm{cfu} / \mathrm{cm}^{2}, 0 \mathrm{cfu} / \mathrm{cm}^{2}$, and $27.5 \mathrm{cfu} / \mathrm{cm}^{2}$, respectively. This finding is beyond the acceptable limits set by Dancer, which states that the mean aerobic count from bacteriological culture of surface samples should be $<5 \mathrm{cfu} / \mathrm{cm}^{2}$ [21]. The reported figure might add an increased risk of infection for patients in the studiedy hospital environment. In addition, the finding calls stakeholders to evaluate and strengthen the practice of infection prevention protocols strictly and to regularly monitor bacteriological quality of the hospital environment.

In this study, the authors tested the antimicrobial resistance profile of the isolates against commonly prescribed agents to highlight their up-to-date profile. Medically important bacteria are continuing posing a growing concern worldwide interim of their management choice. The wide spread use of drugs, especially over/inappropriate/use of antibiotics, unavailability of periodically updated guideline regarding the selection of drugs, and lack of routine microbiological technique to test the antimicrobial susceptibility profile of common agents share their great parts for antimicrobial resistance $[11,12,14]$. In the present study, the majority of gram-positive isolates showed resistance against most of the antibiotics tested. Comparable findings were reported on a study done in Jimma, in which $>80 \%$ resistance was indicated among gram positives [31]. Some $25 \%$ of $S$. aureus isolates were found resistant for cefoxtin which indicates that methicillin-resistant $S$. aureus (MRSA) is ever increasing from time to time. Among gram-negative isolates, E. coli were found $100 \%$ resistant to ampicillin \& cotrimoxazole each. This finding is similar with reports from Gondar and Addis Ababa that showed $>80 \%$ resistance $[11,12]$.

In this study, more than $75 \%$ of the isolates were found multidrug resistant (MDR). This finding is comparable with reports from Hawassa (73.8\%) and Nigeria (65.4\%) [14, 32]. However, our finding is a bit different from a report by Tesfaye et al. from Ayder Hospital (36.5\%) [16]. The resistance among various infectious agents to different antimicrobial drugs has emerged as a cause of public health threat all over the world at a terrifying rate, that really need urgent integrative intervention to curb the problem. Large amounts of antibiotics used for medical therapy, as well as for farm animals resulted in the selection of pathogenic bacteria resistant to multiple drugs (experts opinion).

Due to quite limited variables in this study, it was not possible to determine the associated factors that contribute for bacterial isolation and its load from the hospital environment.

\section{Conclusions}

The present study showed that surfaces and air in the different wards of the studied hospital were found contaminated with different types of bacteria. The bacterial load of surfaces and air were beyond the standard limits. The study also showed that there was an alarmingly high level of antimicrobial resistance for commonly prescribed drugs among isolates. Therefore, interventional strategies to scale 
up the practice of infection prevention in the hospital should be strengthened. Continuous surveillance and monitoring of the types and susceptibility patterns of nosocomial pathogens have to be periodically practiced. Furthermore, largescale studies with sound sample size and design should be considered.

\section{Abbreviations}

CFU: Colony-forming units

CLSI: Clinical Laboratory Standards Institute

FHRH: Felege Hiwot Referral Hospital

ICU: Intensive Care Unit

MDR: Multidrug resistant

NICU: Neonatal Intensive Care Unit

NIs: Nosocomial infections

OT: Operation Theatre

QC: Quality control

SPSS: Statistical Software Package for Social Sciences.

\section{Data Availability}

All data generated during this study are included in this manuscript.

\section{Ethical Approval}

Ethical clearance was obtained from College of Medicine and Health Sciences Ethical Review Board (IRB), Bahir Dar University. Permission was also granted from FHRH administrative body to collect bacteriological samples after adequate explanation about the purpose and importance of the study.

\section{Conflicts of Interest}

The authors declare that they have no conflicts of interest.

\section{Authors' Contributions}

Hailu Getachew, Awoke Derbie, and Daniel Mekonnen were involved in the design, implementation of the study, and preparation of the manuscript. All authors have read and approved the final manuscript.

\section{Acknowledgments}

The authors express our deep appreciation to Bahir Dar University and Felege Hiwot Referral Hospital.

\section{References}

[1] S. S. Magill, J. R. Edwards, W. Bamberg et al., "Multistate pointprevalence survey of health care-associated infections," New England Journal of Medicine, vol. 370, no. 13, pp. 1198-1208, 2014.

[2] M. N. Kurutkan, O. Kara, and I. H. Eraslan, "An implementation on the social cost of hospital acquired infections," International Journal of Clinical and Experimental Medicine, vol. 8, no. 3, pp. 4433-4443, 2015.
[3] D. J. Weber, D. Anderson, and W. A. Rutala, "The role of the surface environment in healthcare-associated infections," Current Opinion in Infectious Diseases, vol. 26, no. 4, pp. 338-344, 2013.

[4] J. B. Sarma and G. U. Ahmed, "Infection control with limited resources: why and how to make it possible?," Indian Journal of Medical Microbiology, vol. 28, no. 1, p. 11, 2010.

[5] S. Melaku, M. Kibret, B. Abera, and S. Gebre-Sellassie, "Antibiogram of nosocomial urinary tract infections in Felege Hiwot referral hospital, Ethiopia," African Health Sciences, vol. 12, no. 2, pp. 134-139, 2012.

[6] M. Ogwang, D. Paramatti, T. Molteni et al., "Prevalence of hospital-associated infections can be decreased effectively in developing countries," Journal of Hospital Infection, vol. 84, no. 2, pp. 138-142, 2013.

[7] U. K. Muhammad, M. A. Isa, and Z. M. Aliyu, "Distribution of potential nosocomial pathogens isolated from environments of four selected hospital in Sokoto, North Western Nigeria," Journal of Microbiology and Biotechnology Research, vol. 3, pp. 139-143, 2013.

[8] A. S. K. Jain, "Recent advances in the management of nosocomial infections," Journal of Medical Research, vol. 9, pp. 1-8, 2007.

[9] G. M. Snyder, K. A. Thom, and J. P. Furuno, "Detection of methicillin-resistant Staphylococcus aureus and vancomycinresistant enterococci by healthcare workers on infection control gown and gloves," Infection Control and Hospital Epidemiology, vol. 29, no. 7, pp. 583-589, 2008.

[10] J. Eze, E. Ekpo, C. Nzotta, N. Asogwa, and N. Egbe, "X-ray equipments and accessories as possible vectors of nosocomial bacteria in Anambra State, Nigeria," Journal of Association of Radiographers of Nigeria, vol. 26, pp. 18-27, 2012.

[11] A. Gelaw, S. S. Gebre, M. Tiruneh, and M. Fentie, "Antimicrobial susceptibility patterns of bacterial isolates from patients with post-operative surgical site infection, health professionals and Environmental samples at a tertiary level hospital," International Journal of Pharmaceutical Sciences and Research, vol. 3, no. 1, pp. 1-9, 2013.

[12] W. Dessie, G. Mulugeta, S. Fentaw, A. Mihret, M. Hassen, and E. Abebe, "Pattern of bacterial pathogens and their susceptibility isolated from surgical site infections at selected referral hospitals, Addis Ababa, Ethiopia," International Journal of Microbiology, vol. 2016, Article ID 2418902, 8 pages, 2016.

[13] C. Genet, G. Kibru, and W. Tsegaye, "Indoor air bacterial load and antibiotic susceptibility pattern of isolates in operating rooms and surgical wards at Jimma University specialized hospital, Southwest Ethiopia," Ethiopian Journal of Health Sciences, vol. 21, no. 1, pp. 9-18, 2011.

[14] L. Diriba, A. Kassaye, and M. Yared, "Antibiotics susceptibility pattern of hospital indoor airborne bacteria in Hawassa University Teaching and Referral Hospital, South Ethiopia," International Journal of Modern Chemistry and Applied Science, vol. 3, no. 1, pp. 287-292, 2016.

[15] M. Hailemariam, M. Birhaneselase, and E. Azerefege, "Bacterial load and antibiotic susceptibility pattern of isolates in operating rooms at Hawassa University Referral Hospital, southern Ethiopia," Journal of Microbiology and Antimicrobials, vol. 8, no. 1, pp. 1-6, 2016.

[16] T. Tesfaye, Y. Berhe, and K. Gebreselassie, "Microbial contamination of operating Theatre at Ayder Referral Hospital, Northern Ethiopia," International Journal of Pharma Sciences and Research, vol. 10, pp. 975-9492, 2015.

[17] S. Fekadu and B. Getachewu, "Microbiological assessment of indoor air of teaching hospital wards: a case of Jimma 
University Specialized Hospital," Ethiopian Journal of Health Sciences, vol. 25, no. 2, pp. 117-122, 2015.

[18] A. Haileamlak, "Preventing healthcare associated infections," Ethiopian Journal of Health Sciences, vol. 21, pp. 1-2, 2011.

[19] A. Abdollahi and S. Mahmoudzadeh, "Microbial profile of air contamination in hospital wards," Iranian Journal of $\mathrm{Pa}$ thology, vol. 7, no. 3, pp. 177-182, 2012.

[20] C. Pasquarella, O. Pitzurra, and A. Savino, "The index of microbial air contamination," Journal of Hospital Infection, vol. 46, no. 4, pp. 241-256, 2000.

[21] S. J. Dancer, "How do we assess hospital cleaning? A proposal for microbiological standards for surface hygiene in hospitals," Journal of Hospital Infection, vol. 56, no. 1, pp. 10-15, 2004.

[22] M. Cheesbrough, Manual of Medical Microbiology, Oxford Press, Britain, UK, 2000.

[23] A. E. Andersson, I. Bergh, J. Karlsson, B. I. Eriksson, and K. Nilsson, "Traffic flow in the operating room: an explorative and descriptive study on air quality during orthopedic trauma implant surgery," American Journal of Infection Control, vol. 40, no. 8, pp. 750-755, 2012.

[24] A. W. Bauer, W. M. M. Kirby, J. C. Sherris, and M. Turck, "Antibiotic susceptibility testing by a standardized single disk method," American Journal of Clinical Pathology, vol. 45, no. 4, pp. 493-496, 1966.

[25] Clinical Laboratory Standards Institute (CLSI), Performance Standards for Antimicrobial Susceptibility Testing, Twenty Second Information Supplement, vol. 35, 2017.

[26] G. Fischer, S. Fodré, and M. Nehéz, "Results of the study to determine marginal pathogen count values in the air of operating rooms," Zeitschrift für die Gesamte Hygiene und ihre Grenzgebiete, vol. 18, no. 10, pp. 729-733, 1972.

[27] A. Maryam, U.-S. Hadiza, and U. M. Aminu, "Characterization and determination of antibiotic susceptibility pattern of bacteria isolated from some fomites in a teaching hospital in northern Nigeria," African Journal of Microbiology Research, vol. 8, no. 8, pp. 814-818, 2014.

[28] Z. Gizaw, M. Gebrehiwot, and C. Yenew, "High bacterial load of indoor air in hospital wards: the case of University of Gondar teaching hospital, Northwest Ethiopia," Multidisciplinary Respiratory Medicine, vol. 11, p. 24, 2016.

[29] T. Shiferaw, L. Gebr-silasse, G. Mulisa et al., "Bacterial indoorair load and its implications for healthcare-acquired infections in a teaching hospital in Ethiopia," International Journal of Infection Control, vol. 12, no. 1, 2016.

[30] C. Genet, G. KIbru, and K. Hemalatha, "Degree of bacterial contamination and antibiotic susceptibility pattern of isolates from housekeeping surfaces in operating rooms and surgical wards at Jimma University Specialized Hospital, south west Ethiopia," Ethiopian Medical Journal, vol. 50, no. 1, pp. 67-74, 2012.

[31] T. Sahile, S. Esseye, G. Beyene, and S. Ali, "Post-surgical infection and antibiotic susceptibility patterns of bacteria isolated from admitted patients with signs of infection at Jimma University Specialized Hospital, Jimma, Ethiopia," International Journal of Tropical Disease \& Health, vol. 17, no. 4, 2016.

[32] C. P. Bhatt, R. Baidya, P. Karki et al., "Multi drug resistance bacterial isolates of surgical site infection," Open Journal of Medical Microbiology, vol. 4, no. 4, pp. 203-209, 2014. 


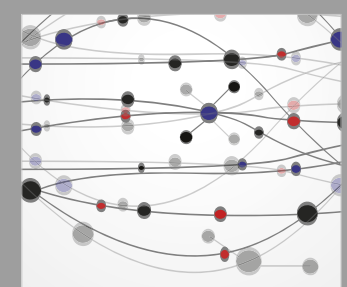

The Scientific World Journal
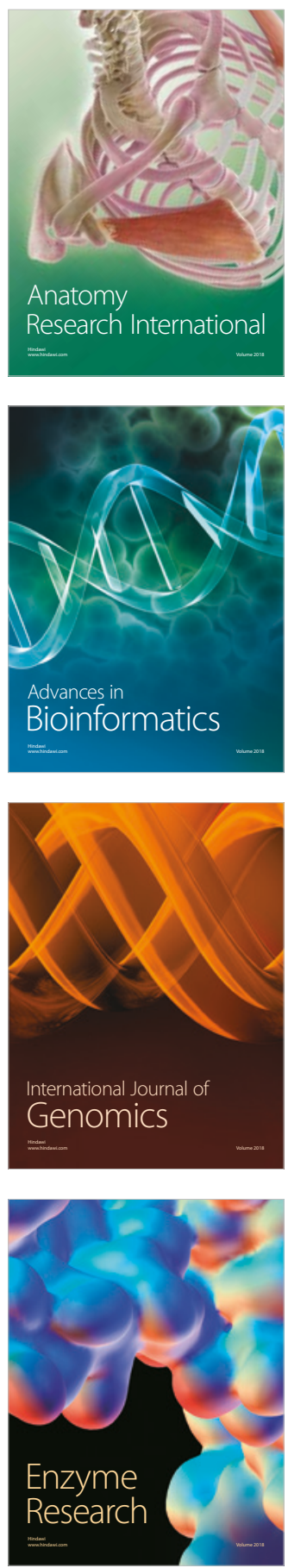
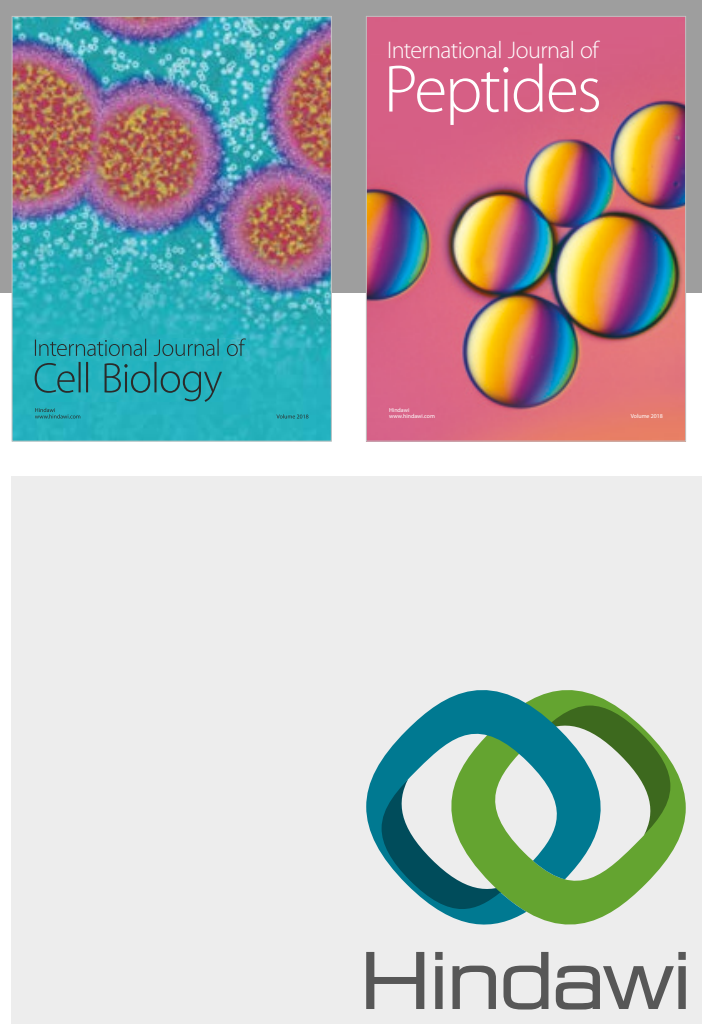

Submit your manuscripts at

www.hindawi.com
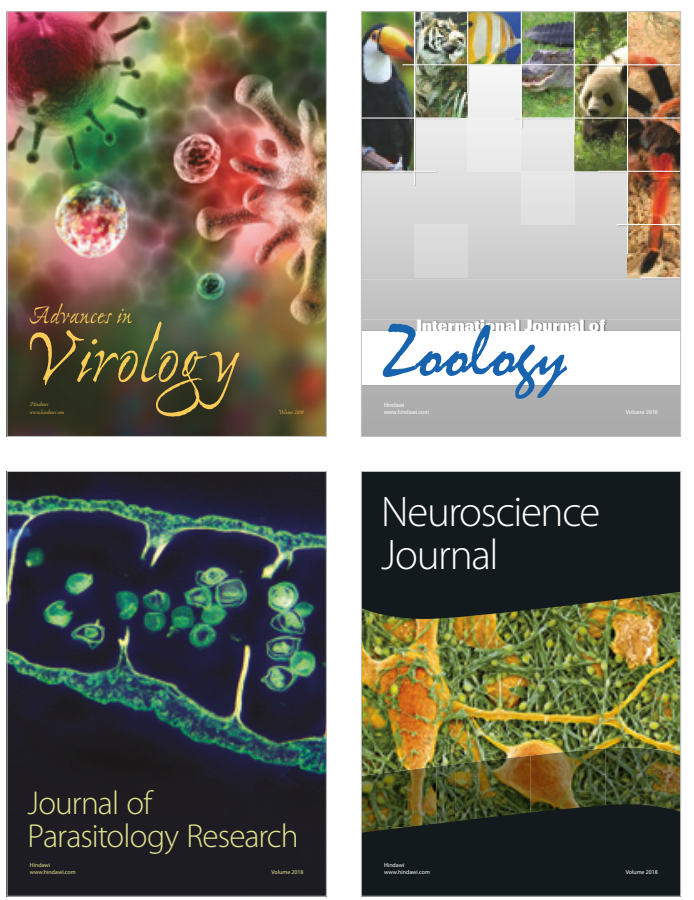
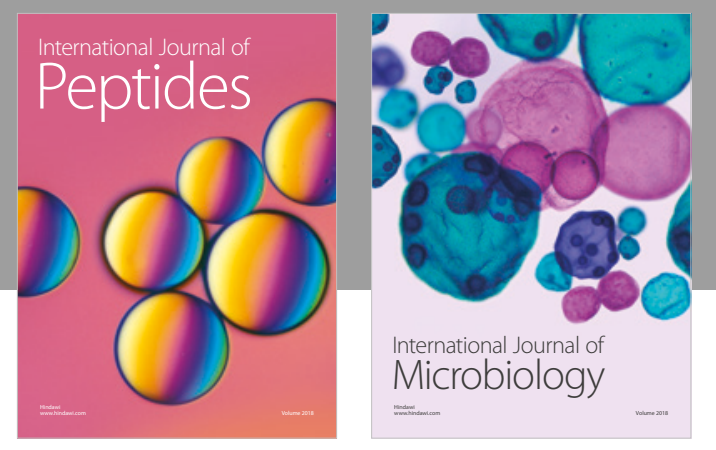

nternational Journal of Microbiology
Journal of
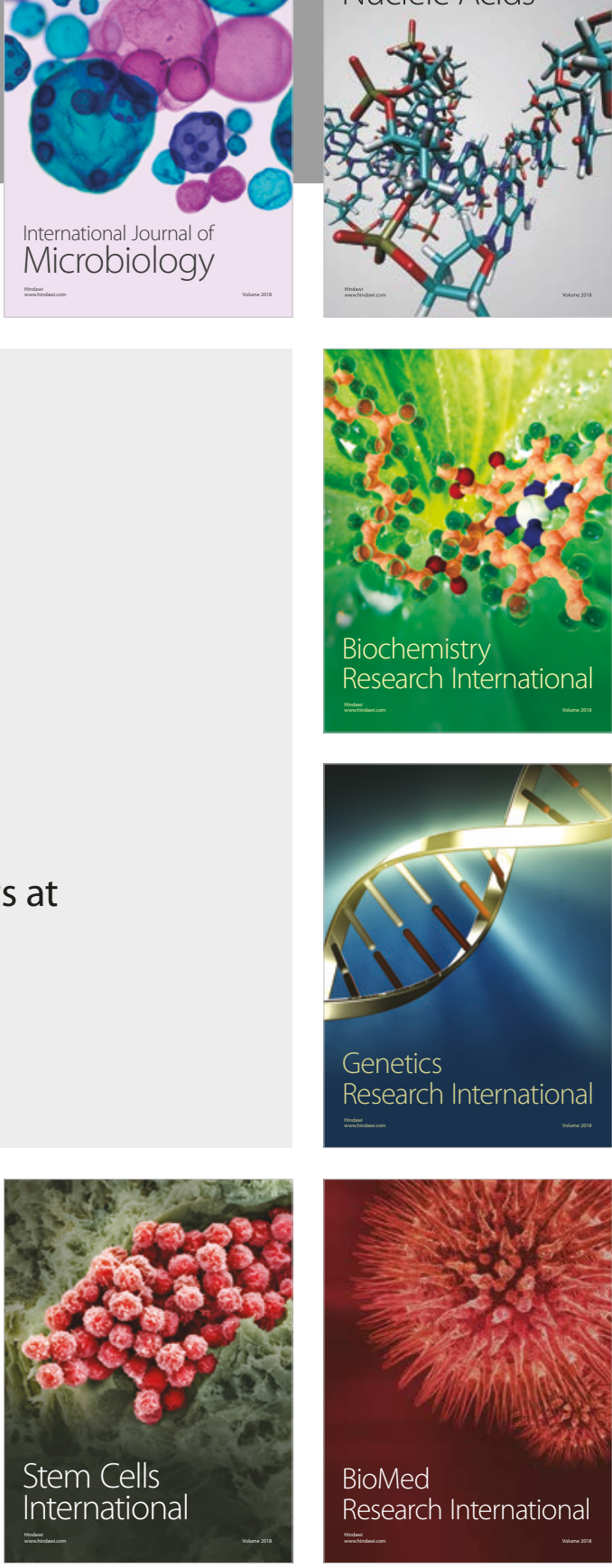
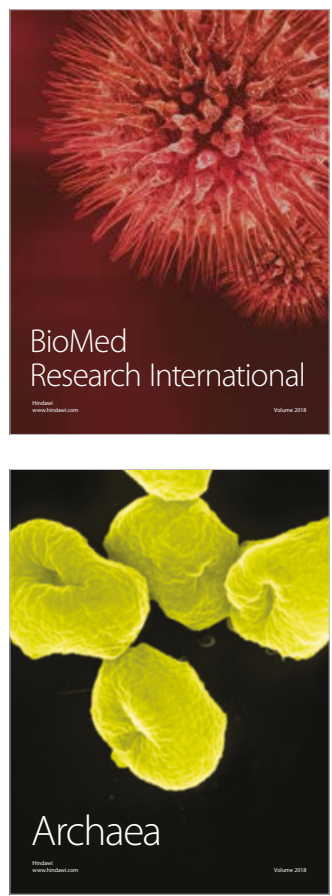